\title{
Innate Inflammation in Parkinson's Disease
}

\author{
V. Hugh Perry \\ School of Biological Sciences, University of Southampton, Southampton, United Kingdom \\ Correspondence: vhp@soton.ac.uk
}

The resident macrophages of the brain-the microglia-are morphologically activated during the progression of Parkinson's disease. Observational studies in human postmortem material and studies in animal models seek to define the contribution that this innate immune response might make to the pathogenesis and rate of progression of Parkinson's disease. We review here some of the key conceptual issues that need to be considered when performing these studies. We highlight the fact that most postmortem studies have not given due consideration to common comorbidities present in patients with Parkinson's disease and also the limitations of attempting to extrapolate from animal models to a chronic progressive neurodegenerative disease in humans that lasts for many years.

It has long been known that degeneration of neurons caused either by acute tissue injury or by chronic neurodegenerative disease is associated with a response by the resident macrophages of the brain, the microglia. Indeed, the microglia are exquisitely sensitive to all forms of brain injury and have been called the sensors of pathology (Kreutzberg 1996). In the injured or diseased brain, the microglia change their morphology and up-regulate, or express de novo, several myeloid antigens: They are then referred to as "activated microglia." An important question is whether these activated innate immune cells contribute to the outcome of injury or disease or whether their response is simply a consequence of the tissue degeneration. If the innate immune response does contribute, we then need to know if this is significant such that it might be a potential therapeutic target in the clinical setting.
As humans live longer and the proportion of aged individuals in the population increases, so does the prevalence of chronic neurodegenerative diseases such as Alzheimer's disease and Parkinson's disease increase. Parkinson's disease (PD) is a common chronic neurodegenerative disease in humans (Lees et al. 2009). The neuropathology of $\mathrm{PD}$ is characterized by the slow and progressive neurodegeneration of dopaminergic cells, which have their cell bodies in the substantia nigra (SN) and axon terminals in the striatum (for a comprehensive description of the neuropathology of PD, see Dickson 2012). As the disease progresses, the degeneration becomes more widespread and involves other regions of the brain (Braak et al. 2003). The affected circuits and the clinical consequences are described in more detail in other articles in this collection (Lanciego et al. 2012; Massano and Bhatia 2012).

Editor: Serge Przedborsk

Additional Perspectives on Parkinson's Disease available at www.perspectivesinmedicine.org

Copyright (C) 2012 Cold Spring Harbor Laboratory Press; all rights reserved; doi: 10.1101/cshperspect.a009373 Cite this article as Cold Spring Harb Perspect Med 2012;2:a009373 
V.H. Perry

Associated with the widespread neurodegeneration, there are activated microglia in the brains of these individuals. The inflammatory response associated with this chronic degenerative disease is unusual because it takes place in an immune privileged organ (Galea et al. 2007), evolves over many years (Lees et al. 2009), and is almost exclusively dominated by cells of the macrophage lineage. We consider here the key conceptual issues in investigating the innate immune response associated with Parkinson's disease with a view to establishing the potential contribution to disease pathogenesis. We first review key components of the innate immune cells of the brain and then consider how we can use this information in the study of the inflammation associated with neuropathology of PD and animal models used to study the disease.

\section{RESIDENT BRAIN MACROPHAGES}

In the healthy adult brain, there are several macrophage populations in different tissue compartments, each with a distinct morphology and phenotype. The most abundant of these macrophages are the microglia, the resident macrophages of the parenchyma. It has long been recognized that these cells have a distinct phenotype when compared with other tissue macrophages, and this has been widely described using terms such as resting, quiescent, down-regulated, and so forth (Perry and Gordon 1991; Ransohoff and Perry 2009). Despite the lack of precision in such terms, they convey an important concept, namely, that the microglia are profoundly influenced by the microenvironment of the brain, and this has had several consequences.

Firstly, microglia in the normal brain do not express a number of cell surface or cytoplasmic antigens typically expressed by other tissue macrophages but only express them in the injured or diseased brain. There are, however, valuable reagents for revealing the microglia populations in normal brain of both experimental animals and humans as has been described in recent reviews (Hanisch and Kettenman 2007; Ransohoff and Perry 2009). It is important to be clear that there are no unique "markers" of the transition from the normal resident state to ac- tivated microglia: The activated phenotype may exist in many different guises, as discussed below, and can only be characterized using a spectrum of reagents.

- The term activated microglia is a useful shorthand, but when considering functional phenotypes, it must be qualified.

- Currently, many descriptions of activated microglia in PD or animal models have used a limited selection of markers and thus, although informing that the microglia have reacted to pathology, tell us little regarding the functional phenotype.

Secondly, the unusual phenotype and morphology suggest that there are molecules expressed in the brain that must influence the microglia. In recent years it has been shown that there are diverse ligands expressed on (CD200, CD47, sialic acids) or secreted by (CX3CL1) neurons that bind to receptors on microglia (CD200R, CD172a; siglecs) (Hoeck et al. 2000; Barclay and Brown 2006; Cardona et al. 2006). These receptors contain a cytoplasmic motif that inhibits the activation of the microglia, so-called ITIM (immunoreceptor tyrosine-based inhibitory motif ) receptors. The density of the ligands expressed by neurons will be reduced during the progression of a neurodegenerative disease and will thus influence the level of inhibitory tone on the microglia. During neurodegeneration, there may also be a shift toward the expression of ITAM (immunoreceptor tyrosine-based activating motif )-bearing receptors such as several of the Fc receptors (Lunnon et al. 2011).

- The changes in expression of neuronal ligands and the receptors that regulate the microglia phenotype in the progression of PD remain to be investigated.

Thirdly, the microglia are distributed throughout the brain, and each cell has its own territory, continually moving its processes to palpate the cell surface of neurons and other cells within the territory (Nimmerjahn et al. 2005). However, the distribution of microglia is not uniform in the brain: The greatest density of microglia in the mouse brain is found in the $\mathrm{SN}$, closely 
followed by the striatum (Lawson et al. 1990). The greater density of microglia in the $\mathrm{SN}$ is associated with a distinct morphology when compared with microglia in other regions. Although to date there is no direct evidence that microglia in the SN are functionally distinct from other microglia, as discussed below, the SN does appear to be particularly sensitive to a challenge with endotoxin LPS (lipopolysaccharide), whose ligand - the toll-like receptor 4 (TLR4) is expressed by microglia. There are some regional differences in microglia cell-surface receptor expression, but those in the SN have not been selectively studied (de Haas et al. 2008).

- It would be of interest to know whether microglia in the SN have a particular phenotype, for example, whether levels of expression of toll-like receptors and their signaling pathway are raised relative to other regions.

The parenchymal microglia have had several different functions attributed to them. During development, they are involved in the phagocytosis of cells undergoing apoptosis as a part of normal brain development (Perry et al. 1985). In the adult, as they constantly monitor their immediate microenvironment palpating the surface of neurons and glia, they are able to phagocytose local debris and act as the first line of defense against tissue damage or infection. It has been suggested that microglia may play a role in the regulation of synapse number during development by recognizing and removing supernumerary synapses tagged with complement proteins (Stevens et al. 2007) and that they play a role in monitoring synaptic integrity in the adult brain (Wake et al. 2009; Tremblay et al. 2010). The concept that microglia are involved in the regulation of synaptic numbers in development, pathology, and synaptic homeostasis has been reviewed elsewhere (Perry and O'Connor 2010). Direct evidence that microglia are key players in the removal of synapses in development or chronic neurodegenerative disease is lacking: The removal of synapses during development appears to be a neuron-autonomous process, and the involvement of microglia in removing degenerating synapses is unproven. The microglia have also been attributed a trophic function in the adult brain, and it has been proposed that the loss of this trophic activity during aging may underpin neurodegenerative disease (Streit 2006). However, given the rather low density of these cells in the gray matter of adult human brain, with an even smaller ratio of microglia to neurons than in rodents (Lawson et al. 1990; Mittelbronn et al. 2001), and the fact that there are larger numbers in the white matter than gray matter in the human brain, it seems unlikely that this is a major function.

Recent evidence shows that the resident microglia are derived from the yolk sac during embryogenesis rather than the bone marrow, indicating a possible unique myeloid lineage (Ginhoux et al. 2010). Several studies using bonemarrow chimeras suggested that the microglia in the adult were slowly replaced by bone-marrow-derived cells, but recent evidence suggests that there is little or no replacement from the blood during adult life even in a number of neurodegenerative conditions (see Ransohoff2007). The microglia numbers appear to be maintained by local low levels of proliferation (Lawson et al. 1992).

- If the microglia are long-lived cells with little replacement from the periphery, it would be of interest to know in chronic neurodegenerative conditions such as PD whether the increased numbers of activated microglia arise from a limited number of precursor cells or whether all microglia have the potential to proliferate.

- The longevity of microglia also suggests that the adult phenotype may have been influenced by events that happened earlier in development, perhaps even in utero, and thus alter the response to subsequent challenges (Bilbo and Schwarz 2009).

In addition to the microglia, there are several other populations of macrophages associated with the brain. There are macrophages present in the peri-vascular space of the parenchymal blood vessels (peri-vascular macrophages), the choroid plexus, the circumventricular organs, and the subarachnoid space (Perry and Gordon 1991; Ransohoff and Perry 2009). These 
V.H. Perry

macrophages are each exposed to a distinct local microenvironment and have a distinct phenotype. Importantly for the present discussion, these cells have the potential to play a significant role in the signaling of systemic inflammatory events to the brain, as discussed below, and thus of potential importance in a neurodegenerative disease typically associated with aging.

- The role of macrophages other than the microglia has not been investigated in PD. It is not known whether these populations expand in number or alter their phenotype in PD or models of PD.

\section{SYSTEMIC INFLAMMATION}

A systemic infection or injury gives rise to an inflammatory response that communicates with the brain, leading to changes in metabolism and behavior collectively known as sickness behavior (Dantzer et al. 2009). These changes in behavior are an important part of our homeostasis and help the individual to fight infection and aid in recovery. Both neural and humoral routes mediate communication from the site of peripheral inflammation to the brain. The neural route may be of particular importance following infection in the thoracic abdominal cavity and involves afferent fibers of the vagus nerve (Pavlov and Tracey 2005). The humoral route involves circulating cytokines that communicate with the brain by one of several routes including signaling at the circumventricular organs, where there is no blood-brain barrier (BBB), signaling across the endothelium of the intact $\mathrm{BBB}$, and via peri-vascular macrophages (Dantzer et al. 2009). Signaling from peripheral inflammation may also occur from the subarachnoid space to the superficial layers of the cortex and shows important age-related changes (Wu et al. 2005, 2008). Each of these routes to the brain involves signaling via microglia.

In the healthy adult brain, the signaling from the periphery to the brain is transient, and there is no evidence that it leads to tissue damage. In brains with ongoing chronic neurodegeneration, there is a growing body of evidence to show that the microglia are not only increased in number and have an activated phenotype, but appear to be "primed" by the ongoing pathology such that systemic inflammation leads to an exaggerated synthesis of pro-inflammatory cytokines (Perry et al. 2007; Cunningham et al. 2009; Field et al. 2010). The switch in the microglia phenotype during systemic inflammation has been described in pre-clinical models of both acute (Palin et al. 2008) and chronic (Cunningham et al. 2005; Lunnon et al. 2011) neurodegeneration. Studies in animal models show that systemic inflammation can lead to exaggerated acute symptoms of brain disease, accelerate disease progression (Cunningham et al. 2005, 2009), and increase neuronal loss (Cunningham et al. 2005; Pott Godoy et al. 2008). Clinical studies in patients with Alzheimer's disease show an association between acute and chronic systemic inflammation and accelerated cognitive decline (Holmes et al. 2009) and increased frequency of behavioral symptoms typical of sickness behavior (Holmes et al. 2011).

- Studies showing the impact of systemic inflammation on the innate immune cells in the diseased brain highlight the need to pay much more attention to peripheral comorbidities in postmortem studies of PD patients and also the role of systemic influences on the immune response described in animal models of PD.

\section{NEUROINFLAMMATION IN PARKINSON'S DISEASE}

The fact that microglia respond and change their morphology, expression of receptors, and secretory products in all forms of CNS damage and disease means that if we are to understand their functional role in the outcome of the disease, we need to define their phenotype carefully at different stages of the disease process. Cells of the macrophage lineage are known to exist in different forms sometimes referred to as "classically activated" (so-called M1 macrophages) after exposure to $\gamma$-interferon, or "alternatively activated" (so-called M2 macrophages) after exposure to interleukin-4 or -13 (Gordon and Taylor 2005; Gordon and Martinez 2010). It is now apparent 
that following tissue injury, they exist in many different phenotypes that cannot be readily divided up into a small number of discrete subsets (Mosser and Edwards 2008). Furthermore, the phenotype is not fixed, and the secretory and cell surface receptor profile of macrophages can be rapidly changed within a few hours both in vitro (Stout et al. 2005) and in vivo (Perry et al. 2007; Stout et al. 2009; Lunnon et al. 2011). Defining the phenotype requires diverse tools and cannot be predicted from a small number of markers detected by immunocytochemistry.

\section{MICROGLIA AND MACROPHAGES}

The presence of activated microglia in the brains of PD patients has been described (McGeer et al. 1988; Banati et al. 1998), but these observations are little more than evidence that there is some form of brain pathology and tell us nothing regarding the contribution that these cells might make to disease progression. The markers commonly used to document the presence of activated microglia-MHC Class II, CD68, and complement receptor type 3-do not inform on the functionality of microglia. Several studies have documented, in a small number of tissue samples, the presence of pro-inflammatory cytokines and other microglia effector molecules, which would suggest that the cells have the potential to exacerbate neuronal injury (Mogi et al. 1994a,b; Hunot et al. 1996). In vivo imaging using positron emission tomography (PET) and the ligand PK-11195 that binds the peripheral benzodiazapine receptor (also known as the translocator protein) expressed on cells of the macrophage lineage in the brain suggests widespread activated microglia in PD patients (Gerhard et al. 2006). The levels of brain PK-11195 labeling did not correlate with clinical disease. There is no evidence that the PK-11195 ligand differentiates between phenotypically distinct microglia nor that it binds only to microglia. Thus the microglia could change their phenotype without changing their PK-11195 binding or there may be disease-related up-regulation of peripheral benzodiazepine receptors in brain cells other than microglia. There are no studies that have characterized the possible changes in peri-vascular or other non-microglia macrophage populations in the brains of PD patients.

Several variables have to be considered that may influence the microglia phenotype in postmortem material, and they have received little attention in neuropathological studies. PD is a late-onset disease that is likely to have evolved over several decades, and end-stage pathology will inevitably be associated with widespread neuronal degeneration and microglia activation. The age at death of individuals suffering from PD is in their mid-70s (Kempster et al. 2007); importantly, this is an aged nervous system with well-documented evidence that microglia are progressing toward a more activated phenotype (Perry et al. 1993; DiPatre and Gelman 1997). The microglia in the diseased brain are also likely to be influenced by systemic disease that may have existed some time before death, and the cause of death will also have an impact. Agematched controls with similar causes of death are important, but the interactions between systemic inflammation and a healthy brain and systemic inflammation and a diseased brain are very different with regard to the resident macrophage population.

It has been shown in postmortem material from patients who died with sepsis that the microglia expressed higher levels of CD68 than in people who did not (Lemstra et al. 2007).

Patients with PD have several symptoms that may induce a systemic inflammatory response not only at the terminal stage of the disease but also at earlier times. Constipation is an early symptom in PD patients (Chaudhuri and Naidu 2008). Chronic constipation results in changes in the gut flora, an increase in the permeability of the gut epithelium, and evidence of bacterial antigens escaping from the gut with disturbances of immune function (Khalif et al. 2005). Treatment of the constipation leads to a restoration of epithelium integrity and normalization of immune parameters. The difficulties in swallowing particularly in late-stage PD may lead to aspiration pneumonia, a common cause of death in PD patients (Pennington et al. 2010). Lung inflammation will also be associated with a peripheral inflammatory response that may have an impact on the CNS. 
V.H. Perry

- Neuropathology studies in PD patients have paid scant attention to the comorbidities that might influence the microglia phenotype in postmortem studies

\section{T CELLS}

The cytokine profile of microglia is critically influenced by interactions with different populations of $\mathrm{T}$ cells and the cytokines they secrete. Both CD4- and CD8-positive T cells have been reported to be present in the brains of individuals with PD (McGeer et al. 1988; Brochard et al. 2009), but these studies have not investigated whether these cells express markers of activated $\mathrm{T}$ cells. Recent evidence from genome-wide association studies (GWAS) indicates that HLA genes are associated with PD (International Parkinson Disease Genomics Consortium 2011), suggesting that there may be an acquired immune component associated with the disease ( for a comprehensive discussion of adaptive immunity and PD, see Mosley et al. 2012). Whether this immune component reflects on immune response in the brain or in peripheral tissues is not known.

- There is a need to know whether the T cells present in the brains of patients who died with PD express activation markers and can be further characterized.

- Changes in T-cell numbers and activation state are sensitive to systemic comorbidities, such as constipation, and need to be taken into account when evaluating $\mathrm{T}$-cell populations in the brain or periphery of PD patients.

\section{EPIDEMIOLOGY}

Epidemiological studies have provided some evidence suggesting that the innate immune response seen in the brains of patients with chronic neurodegenerative disease is more than simply a consequence of neuronal degeneration. A recent meta-analysis of studies on patients with Alzheimer's concluded that those individuals who take non-steroidal anti-inflammatory drugs (NSAIDs) for extended periods of time, a period of at least several years, are in some way protected from the onset or progression of $\mathrm{AD}$ (Etminan et al. 2003). A similar meta-analysis of studies on cohorts of PD patients has concluded that there is evidence that non-aspirin NSAIDs are protective (Gagne and Powers 2010). It is not clear where these drugs exert their effects: It may be either within the CNS or equally on systemic inflammatory components. If systemic disease is involved in $\mathrm{PD}$ progression, as recent evidence from studies in AD suggests, there are likely many signaling routes from systemic inflammation to the brain, and although NSAIDs may block some pathways, they may actually enhance other possible signaling pathways (Teeling et al. 2010).

\section{NEUROINFLAMMATION IN PRE-CLINICAL MODELS OF PARKINSON'S DISEASE}

Advances in our understanding of the contribution of neuroinflammation to PD pathogenesis could be made by the study of pre-clinical models. However, this makes the assumption that the models accurately reflect the neuropathology of PD in humans or significant components of it. Numerous models of PD exist using toxins to mimic aspects of an environmental challenge, transgenic models to mimic aspects of the familial forms of PD, and models with an inflammatory challenge. But at the present time, no single model reproduces the slow and progressive degeneration of dopaminergic cells of the SN. It seems unlikely that a model will be widely used in the laboratory if the degeneration takes place over many years, but a minimal requirement is that degeneration should be progressive at least over weeks and months rather than a few hours or days. We might expect to see first the degeneration of dopaminergic terminals followed by the demise of the cell bodies in the $\mathrm{SN}$, and as the disease progresses the involvement of other systems.

\section{TOXIN MODELS}

The selective acute degeneration of dopaminergic cells in the $\mathrm{SN}$ can be induced by the toxins 6-hydroxydopamine (6OHDA), 1-methyl-4phenyl-1,2,3,6-tetrahydropyridine (MPTP), and rotenone. In all of these models in laboratory 
rodents, the $\mathrm{SN}$ dopaminergic cells degenerate over a period of a few days. A recent study comparing the commonly used intrastriatal or medial forebrain injection of 6OHDA shows the rapid degeneration induced by the toxin, and this is accompanied by the activation of the microglia as assessed by the up-regulation of the complement type 3 receptor (Walsh et al. 2011). Similarly, MPTP-induced neurodegeneration is associated with the presence of activated microglia (McGeer et al. 2003; Suguma et al. 2003). Many studies of this genre have focused on the use of a limited number of reagents to provide evidence that the microglia are morphologically activated and respond to the presence of the degenerating neurons: This adds little to the concept of how neuroinflammation might contribute to the disease. Descriptions of the molecules secreted by microglia in these acute degeneration models are numerous (for references, see Hirsch and Hunot 2009). However, the repertoire of molecules studied is relatively limited, and extrapolation of studies of mRNA expression to protein expression cannot be assumed (Depino et al. 2003). Attempts to evaluate the contribution of the innate inflammatory response to the acute degeneration of $\mathrm{SN}$ neurons comes from studies in which microglia/ macrophage function has been modulated, for example, by minocycline. The results are variable and may be highly model dependent ( $\mathrm{Wu}$ et al. 2002; Sriram et al. 2006).

Several studies have investigated whether there are interactions between systemic inflammation and the inflammatory response induced by a toxic injury, and it has been shown that chronic systemic interleukin-1 $\beta$ levels will lead to an increase in the number of SN neurons that degenerate (Pott Godoy et al. 2008). These studies provide proof-of-principle that in the context of the death of dopaminergic neurons, local brain inflammation and systemic inflammation interact, but the direct relevance to PD remains to be established.

- The models of PD induced by acute toxins have had little predictive power when it comes to the translation of neuroprotective or regenerative strategies in PD (Hirsch and
Hunot 2009; Dawson et al. 2010). It is too early to tell whether the inflammatory processes described in these models, sometimes with the addition of a systemic inflammatory component, will have translational value, but consideration of the significant limitations of these models must be borne in mind.

\section{TRANSGENIC MODELS}

The identification of both autosomal-dominant and -recessive genes in familial PD has been a major and exciting part of research into the etiology and pathogenesis of Parkinson's disease. Identification of these genes holds promise for the development of mouse models in which expression of these genes driven by the appropriate promoters might give rise to chronic neurodegeneration of the dopaminergic neurons. At the present time, none of these models has lived up to this promise, as reviewed elsewhere (Dawson et al. 2010). The lack of neurodegeneration in these models severely limits their value for the study of neuroinflammation in PD. One might argue that they represent early stages of the disease evolution and may be of value for investigating the impact of local or systemic inflammation in precipitating degeneration of the dopaminergic or other neurons that are already under genetically induced stress (Gao et al. 2011).

A few studies have been performed on neuroinflammation in transgenic models. For example, Su et al. (2008) report that there is evidence of microglia activation and a small increase in TNF- $\alpha$ mRNA levels in the SN of mice overexpressing human wild-type $\alpha$-synuclein. The small change in TNF- $\alpha$ mRNA levels in vivo contrasts dramatically with the levels of TNF- $\alpha$ protein induced in microglia in vitro by addition of the wild-type $\alpha$-synuclein protein to the cultures (Su et al. 2008), highlighting the differences between the gradual accumulation of mutant $\alpha$-synuclein and the instantaneous addition to microglia in culture. These studies also raise the important question as to what is the appropriate concentration of $\alpha$-synuclein to add to the cultured microglia, because the concentration that increased cytokine production was at least 10 -fold higher than con- 
V.H. Perry

centrations found in the cerebrospinal fluid ( $\mathrm{Su}$ et al. 2008; Aerts et al. 2011).

A further interesting contrast is the lack of neurodegeneration observed in transgenic models of PD and models in which a viral vector has been used to introduce either wild-type or mutated human $\alpha$-synuclein into neurons, which does induce neurodegeneration (Kirik et al. 2002, 2003). One possible explanation for the difference between the transgenic models and viral models is that the virus induces the protein in glia as well as neurons, suggesting that the neurodegeneration is not a neuron-autonomous event. However, it is also possible that the inflammatory response to the viral vector synergizes with the effect of the misfolded protein and promotes neurodegeneration.

- The murine transgenic models of PD offer new routes to investigating whether inflammation induced by diverse environmental factors-for example, inflammation, infection, and environmental toxins - can lead to the onset or progression of a neurodegenerative disease when neuronal function might already be compromised by the presence of a mutated protein in dopaminergic or other neuronal populations.

\section{INFLAMMATORY AGENT TOXICITY}

A model for the study of innate immunity in PD involves the injection of LPS directly into the vicinity of the SN (Herrera et al. 2000). In contrast to acute LPS injections into other sites in the CNS, the SN injection leads to death of dopaminergic neurons while sparing other neurons, and a similar selective loss of dopaminergic neurons is obtained following exposure to systemic LPS either in utero (Ling et al. 2002) or in adult mice (Qin et al. 2007). The selective demise of the dopaminergic neurons presumably arises because of their intrinsic sensitivity and the properties of the local microglia and astrocyte populations, each of which has yet to be fully defined. The mechanisms by which LPS induces degeneration are controversial, but TNF- $\alpha$ appears to be necessary (McCoy et al. 2006). It should be recognized that the amounts of LPS administered systemically are models of sepsis rather than more typical systemic infection.

- Further dissection of the minimal requirement for local and systemic innate inflammation-induced dopaminergic neurodegeneration could be an important route to defining factors that prime the cells in SN for degeneration or synergize with other risk factors

\section{WHAT ACTIVATES THE MICROGLIA?}

A key issue for understanding the role of innate inflammation in the CNS in the pathogenesis of $\mathrm{PD}$ is to discover what are the stimuli that lead to the activation of microglia, in particular, those that drive them to a phenotype that promotes neurodegeneration. Neuronal degeneration per se will lead to the generation of numerous molecules that may activate myeloid cells (Hanisch and Kettenmann 2007) and release the inhibitory tone on microglia as discussed above. In vitro studies have shown that neuromelanin (Wilms et al. 2003) and $\alpha$-synuclein aggregates (Zhang et al.2005) lead to activation of the microglia and the generation of potentially neurotoxic molecules. However, the mismatch between in vitro and in vivo experimental approaches seems to have attracted little critical appraisal despite the fact that the same issues pertain in a number of other protein misfolding diseases. The response of a cell of the macrophage lineage is critically dependent not only on the concentration of the stimulus but also the rate of change of the stimulus, any prior stimulation, and the local microenvironment. It seems very unlikely that a microglia cell will respond in the same manner to the slow accumulation of $\alpha$-synuclein aggregates or slow progressive release of neuromelanin as it will to the sudden addition of these agents to a culture plate, a microenvironment in which the microglia have already been acutely removed from the tonic inhibition provided by ligands expressed on the surrounding neurons in vivo.

- In vitro studies designed to discover the critical factors involved in the activation of microglia during neurodegeneration need to be more closely aligned with in vivo experimental paradigms. 


\section{CONCLUSION}

The contribution of innate inflammation to modifying the onset or progression of $\mathrm{PD}$ is not yet established. It has, however, become clear that environmental factors, both internal and external to an individual, have the potential to influence the innate immune cells of the brain in both health and disease. The progression of PD likely results from the interaction of many diverse environmental insults, and innate immune cells in the brain may respond to signals from the periphery leading to the generation of neurotoxic molecules. Observational studies on PD postmortem tissue will need to take into account the systemic factors that might influence the pathology. A significant challenge will be to refine the animal models of PD so that they reflect the slow and inexorable degeneration of dopaminergic cells.

\section{ACKNOWLEDGMENTS}

The work in the author's laboratory is supported by the Wellcome Trust, MRC, and EU.

\section{REFERENCES}

* Reference is also in this collection.

Aerts MB, Esselink RA, Abdo WF, Bloem BR, Verbeek MM 2011. CSF $\alpha$-synuclein does not differentiate between parkinsonian disorders. Neurobiol Aging 33: 430.e1430.e3.

Banati RB, Daniel SE, Blunt SB. 1998. Glial pathology but absence of apoptotic nigral neurons in long-standing Parkinson's disease. Mov Disord 13: 221-27.

Barclay AN, Brown MH. 2006. The SIRP family of receptors and immune regulation. Nat Rev Immunol 6: 457-464.

Bilbo SD, Schwarz JM. 2009. Early-life programming of later-life brain and behavior: A critical role for the immune system. Front Behav Neurosci 3: 14.

Braak H, Del Tredici K, Rüb U, de Vos RA, Jansen Steur EN, Braak E. 2003. Staging of brain pathology related to sporadic Parkinson's disease. Neurobiol Aging 24: $197-$ 211.

Brochard V, Combadière B, Prigent A, Laouar Y, Perrin A, Beray-Berthat V, Bonduelle O, Alvarez-Fischer D, Callebert J, Launay JM, et al. 2009. Infiltration of CD4+ lymphocytes into the brain contributes to neurodegeneration in a mouse model of Parkinson disease. J Clin Invest 119: $182-192$.

Cardona AE, Pioro EP, Sasse ME, Kostenko V, Cardona SM, Dijkstra IM, Huang D, Kidd G, Dombrowski S, Dutta R, et al. 2006. Control of microglial neurotoxicity by the fractalkine receptor. Nat Neurosci 9: 917-924.

Chaudhuri KR, Naidu Y. 2008. Early Parkinson's disease and non-motor issues. J Neurol 255: 33-38.

Cunningham C, Wilcockson DC, Campion S, Lunnon K, Perry VH. 2005. Central and systemic endotoxin challenges exacerbate the local inflammatory response and increase neuronal death during chronic neurodegeneration. J Neurosci 25: 9275-9284.

Cunningham C, Campion S, Lunnon K, Murray CL, Woods JF, Deacon RM, Rawlins JN, Perry VH. 2009. Systemic inflammation induces acute behavioral and cognitive changes and accelerates neurodegenerative disease. Biol Psychiatry 65: 304-312.

Dantzer R, O'Connor JC, Freund GG, Johnson RW, Kelley KW. 2009. From inflammation to sickness and depression: When the immune system subjugates the brain. Nat Rev Neurosci 9: 46-56.

Dawson TM, Ko HS, Dawson VL. 2010. Genetic animal models of Parkinson's disease. Neuron 66: 646-661.

de Haas AH, Boddeke HW, Biber K. 2008. Region-specific expression of immunoregulatory proteins on microglia in the healthy CNS. Glia 56: 888-894.

Depino AM, Earl C, Kaczmarczyk E, Ferrari C, Besedovsky H, del Rey A, Pitossi FJ, Oertel WH. 2003. Microglial activation with atypical proinflammatory cytokine expression in a rat model of Parkinson's disease. Eur J Neurosci 18: 2731-2742.

* Dickson DW. 2012. Parkinson's disease and parkinsonism: Neuropathology. Cold Spring Harb Perspect Med doi: 10.1101/cshperspect.a009258.

DiPatre PL, Gelman BB. 1997. Microglial cell activation in aging and Alzheimer disease: Partial linkage with neurofibrillary tangle burden in the hippocampus. J Neuropathol Exp Neurol 56: 143-149.

Etminan M, Gill S, Samii A. 2003. Effect of non-steroidal anti-inflammatory drugs on risk of Alzheimer's disease: Systematic review and meta-analysis of observational studies. BMJ 327: 128.

Field R, Campion S, Warren C, Murray C, Cunningham C. 2010. Systemic challenge with the TLR3 agonist poly I:C induces amplified IFN $\alpha / \beta$ and IL- $1 \beta$ responses in the diseased brain and exacerbates chronic neurodegeneration. Brain Behav Immun 24: 996-1007.

Gagne JJ, Power MC. 2010. Anti-inflammatory drugs and risk of Parkinson disease: A meta-analysis. Neurology 74: 995-1002.

Galea I, Bechmann I, Perry VH. 2007. What is immune privilege (not)? Trends Immunol 28: 12-18.

Gao HM, Zhang F, Zhou H, Kam W, Wilson B, Hong JS. 2011. Neuroinflammation and a-synuclein dysfunction potentiate each other driving chronic progression of neurodegeneration in a mouse model of Parkinson's disease. Environ Health Perspect 119: 807-814.

Gerhard A, Pavese N, Hotton G, Turkheimer F, Es M, Hammers A, Eggert K, Oertel W, Banati RB, Brooks DJ. 2006 In vivo imaging of microglial activation with $\left[{ }^{11} \mathrm{C}\right](R)$ PK11195 PET in idiopathic Parkinson's disease. Neurobiol Dis 21: 404-412.

Ginhoux F, Greter M, Leboeuf M, Nandi S, See P, Gokhan S, Mehler MF, Conway SJ, Ng LG, Stanley ER, et al. 2010. 
V.H. Perry

Fate mapping analysis reveals that adult microglia derive from primitive macrophages. Science 330: 841-845.

Gordon S, Martinez FO. 2010. Alternative activation of macrophages: Mechanism and functions. Immunity 32: $593-$ 604.

Gordon S, Taylor PR. 2005. Monocyte and macrophage heterogeneity. Nat Rev Immunol 5: 953-964.

Hanisch UK, Kettenmann H. 2007. Microglia: Active sensor and versatile effector cells in the normal and pathologic brain. Nat Neurosci 10: 1387-1394.

Herrera AJ, Castano A, Venero JL, Cano J, Machado A. 2000. The single intranigral injection of LPS as a new model for studying the selective effects of inflammatory reactions on dopaminergic system. Neurobiol Dis 7: 429-447.

Hirsch EC, Hunot S. 2009. Neuroinflammation in Parkinson's disease: A target for neuroprotection? Lancet Neurol 8: $382-397$.

Hoek RM, Ruuls SR, Murphy CA, Wright GJ, Goddard R, Zurawski SM, Blom B, Homola ME, Streit WJ, Brown $\mathrm{MH}$, et al. 2000. Down-regulation of the macrophage lineage through interaction with OX2 (CD200). Science 290: $1768-1771$

Holmes C, Cunningham C, Zotova E, Woolford J, Dean C, Kerr S, Culliford D, Perry VH. 2009. Systemic inflammation and disease progression in Alzheimer disease. Neurology 73: 768-774.

Holmes C, Cunningham C, Zotova E, Culliford D, Perry VH. 2011. Proinflammatory cytokines, sickness behavior, and Alzheimer disease. Neurology 77: 212-218.

Hunot S, Boissiere F, Faucheux B, Brugg B, Mouatt-Prigent A, Agid Y, Hirsch EC. 1996. Nitric oxide synthase and neuronal vulnerability in Parkinson's disease. Neuroscience 72: 355-363.

International Parkinson Disease Genetics Consortium. 2011. Imputation of sequence variants for identification of genetic risks for Parkinson's disease: A meta-analysis of genome-wide association studies. Lancet 377: 641-649.

Kempster PA, Williams DR, Selikhova M, Holton J, Revesz T, Lees AJ. 2007. Patterns of levodopa response in Parkinson's disease: A clinico-pathological study. Brain 130: 2123-2128.

Khalif IL, Quigley EM, Konovitch EA, Maximova ID. 2005. Alterations in the colonic flora and intestinal permeability and evidence of immune activation in chronic constipation. Dig Liver Dis 37: 838-849.

Kirik D, Rosenblad C, Burger C, Lundberg C, Johansen TE, Muzyczka N, Mandel RJ, Bjorklund A. 2002. Parkinsonlike neurodegeneration induced by targeted overexpression of $\alpha$-synuclein in the nigrostriatal system. J Neurosci 22: $2780-2791$.

Kirik D, Annett LE, Burger C, Muzyczka N, Mandel RJ, Bjorklund A. 2003. Nigrostriatal $\alpha$-synucleinopathy induced by viral vector-mediated overexpression of human $\alpha$-synuclein: A new primate model of Parkinson's disease. Proc Natl Acad Sci 100: 2884-2889.

Kreutzberg GW. 1996. Microglia: A sensor for pathological events in the CNS. Trends Neurosci 19: 312-318.

* Lanciego JL, Luquin N, Obeso JA. 2012. Functional neuroanatomy of the basal ganglia. Cold Spring Harb Perspect Med doi: 10.1101/cshperspect.a009621.
Lawson LJ, Perry VH, Dri P, Gordon S. 1990. Heterogeneity in the distribution and morphology of microglia in the normal adult mouse brain. Neuroscience 39: 151-170.

Lawson LJ, Perry VH, Gordon S. 1992. Turnover of resident microglia in the normal adult mouse brain. Neuroscience 48: 405-415.

Lees AJ, Hardy J, Revesz T. 2009. Parkinson's disease. Lancet 373: $2055-2066$

Lemstra AW, Groen in’t Woud JC, Hoozemans JJ, van Haastert ES, Rozemuller AJ, Eikelenboom P, van Gool WA. 2007. Microglia activation in sepsis: A case-control study. J Neuroinflammation 4: 4.

Ling Z, Gayle DA, Ma SY, Lipton JW, Tong CW, Hong JS, Carvey PM. 2002. In utero bacterial endotoxin exposure causes loss of tyrosine hydroxylase neurons in the postnatal rat midbrain. Mov Disord 17: 116-124.

Lunnon K, Teeling JL, Tutt AL, Cragg MS, Glennie MJ, Perry VH. 2011. Systemic inflammation modulates Fc receptor expression on microglia during chronic neurodegeneration. J Immunol 186: 7215-7224.

* Massano J, Bhatia KP. 2012. Clinical approach to Parkinson's disease: Features, diagnosis, and principles of management. Cold Spring Harb Perspect Med doi: 10.1101/ cshperspect.a008870.

McCoy MK, Martinez TN, Ruhn KA, Szymkowski DE, Smith CG, Botterman BR, Tansey KE, Tansey MG. 2006. Blocking soluble tumor necrosis factor signaling with dominant-negative tumor necrosis factor inhibitor attenuates loss of dopaminergic neurons in models of Parkinson's disease. J Neurosci 26: 9365-9375.

McGeer PL, Itagaki S, Boyes BE, McGeer EG. 1988. Reactive microglia are positive for HLA-DR in the substantia nigra of Parkinson's and Alzheimer's disease brains. Neurology 38: $1285-1291$.

McGeer PL, Schwab C, Parent A, Doudet D. 2003. Presence of reactive microglia in monkey substantia nigra years after 1-methyl-4-phenyl-1,2,3,6-tetrahydropyridine administration. Ann Neurol 54: 599-604.

Mittelbronn M, Dietz K, Schluesener HJ, Meyermann R. 2001. Local distribution of microglia in the normal adult human central nervous system differs by up to one order of magnitude. Acta Neuropathol 101: 249-255.

Mogi M, Harada M, Riederer P, Narabayashi H, Fujita K, Nagatsu T. 1994a. Tumor necrosis factor- $\alpha$ (TNF- $\alpha)$ increases both in the brain and in the cerebrospinal fluid from parkinsonian patients. Neurosci Lett 165: 208-210.

Mogi M, Harada M, Kondo J, Riederer P, Inagaki H, Minami M, Nagatsu T. 1994b. Interleukin-1 $\beta$, interleukin-6, epidermal growth factor and transforming growth factor- $\alpha$ are elevated in the brain from parkinsonian patients. Neurosci Lett 180: 147-150.

* Moseley RL, Hutter-Saunders JA, Stone DK, Gendelman HE. 2012. Inflammation and adaptive immunity in Parkinson's disease. Cold Spring Harb Perspect Med doi: 10.1101/cshperspect.a009381.

Mosser DM, Edwards JP. 2008. Exploring the full spectrum of macrophage activation. Nat Rev Immunol 8: 958-969.

Nimmerjahn A, Kirchhoff F, Helmchen F. 2005. Resting microglial cells are highly dynamic surveillants of brain parenchyma in vivo. Science 308: 1314-1318. 
Palin K, Cunningham C, Forse P, Perry VH, Platt N. 2008 Systemic inflammation switches the inflammatory cytokine profile in CNS Wallerian degeneration. Neurobiol Dis 30: 19-29.

Pavlov VA, Tracey KJ. 2005. The cholinergic anti-inflammatory pathway. Brain Behav Immun 19: 493-499.

Pennington S, Snell K, Lee M, Walker R. 2010. The cause of death in idiopathic Parkinson's disease. Parkinsonism Relat Disord 16: 434-437.

Perry VH, Gordon S. 1991. Macrophages and the nervous system. Int Rev Cytol 125: 203-244.

Perry VH, O'Connor V. 2010. The role of microglia in synaptic stripping and synaptic degeneration: A revised perspective. ASN Neuro 14: e00047.

Perry VH, Hume DA, Gordon S. 1985. Immunohistochemical localization of macrophages and microglia in the adult and developing mouse brain. Neuroscience 15: 313-326.

Perry VH, Matyszak MK, Fearn S. 1993. Altered antigen expression of microglia in the aged rodent CNS. Glia 7: 60-67.

Perry VH, Cunningham C, Holmes C. 2007. Systemic infections and inflammation affect chronic neurodegeneration. Nat Rev Immunol 7: 161-167.

Pott Godoy MC, Tarelli R, Ferrari CC, Sarchi MI, Pitossi FJ. 2008. Central and systemic IL-1 exacerbates neurodegeneration and motor symptoms in a model of Parkinson's disease. Brain 131: 1880-1894.

Qin L, Wu X, Block ML, Liu Y, Breese GR, Hong JS, Knapp DJ, Crews FT. 2007. Systemic LPS causes chronic neuroinflammation and progressive neurodegeneration. Glia 55: $453-462$.

Ransohoff RM. 2007. Microgliosis: The questions shape the answers. Nat Neurosci 10: 1507-1509.

Ransohoff RM, Perry VH. 2009. Microglial physiology: Unique stimuli, specialized responses. Anпu Rev Immunol 227: 119-145.

Sriram K, Miller DB, O'Callaghan JP. 2006. Minocycline attenuates microglial activation but fails to mitigate striatal dopaminergic neurotoxicity: Role of tumor necrosis factor- $\alpha$. J Neurochem 96: 706-718.

Stevens B, Allen NJ, Vazquez LE, Howell GR, Christopherson KS, Nouri N, Micheva KD, Mehalow AK, Huberman AD, Stafford B, et al. 2007. The classical complement cascade mediates CNS synapse elimination. Cell 131: 1164-1178.

Stout RD, Jiang C, Matta B, Tietzel I, Watkins SK, Suttles J. 2005. Macrophages sequentially change their functional phenotype in response to changes in microenvironmental influences. J Immunol 175: 342-349.

Stout RD, Watkins SK, Suttles J. 2009. Functional plasticity of macrophages: In situ reprogramming of tumor-associated macrophages. J Leukoc Biol 86: 1105-1109.
Streit WJ. 2006. Microglial senescence: Does the brain's immune system have an expiration date? Trends Neurosci 29: 506-510.

Su X, Maguire-Zeiss KA, Giuliano R, Prifti L, Venkatesh K, Federoff HJ. 2008. Synuclein activates microglia in a model of Parkinson's disease. Neurobiol Aging 29: 1690 1701.

Sugama S, Yang L, Cho BP, DeGiorgio LA, Lorenzl S, Albers DS, Beal MF, Volpe BT, Joh TH. 2003. Age-related microglial activation in 1-methyl-4-phenyl-1,2,3,6-tetrahydropyridine (MPTP)-induced dopaminergic neurodegeneration in C57BL/6 mice. Brain Res 964: 288-294.

Teeling JL, Cunningham C, Newman TA, Perry VH. 2010. The effect of non-steroidal anti-inflammatory agents on behavioural changes and cytokine production following systemic inflammation: Implications for a role of COX-1. Brain Behav Immun 24: 409-419.

Tremblay ME, Lowery RL, Majewska AK. 2010. Microglial interactions with synapses are modulated by visual experience. PLoS Biol 8: e1000527.

Wake H, Moorhouse AJ, Jinno S, Kohsaka S, Nabekura J. 2009. Resting microglia directly monitor the functional state of synapses in vivo and determine the fate of ischemic terminals. J Neurosci 29: 3974-3980.

Walsh S, Finn DP, Dowd E. 2011. Time-course of nigrostriatal neurodegeneration and neuroinflammation in the 6hydroxydopamine-induced axonal and terminal lesion models of Parkinson's disease in the rat. Neuroscience 175: $251-261$.

Wilms H, Rosenstiel P, Sievers J, Deuschl G, Zecca L, Lucius R. 2003. Activation of microglia by human neuromelanin is NF- $\mathrm{KB}$ dependent and involves p38 mitogen-activated protein kinase: Implications for Parkinson's disease. $F A$ SEB J 17: 500-502.

Wu DC, Jackson-Lewis V, Vila M, Tieu K, Teismann P, Vadseth C, Choi DK, Ischiropoulos H, Przedborski S. 2002. Blockade of microglial activation is neuroprotective in the 1-methyl-4-phenyl-1,2,3,6-tetrahydropyridine mouse model of Parkinson disease. J Neurosci 22: 1763-1771.

Wu Z, Zhang J, Nakanishi H. 2005. Leptomeningeal cells activate microglia and astrocytes to induce IL-10 production by releasing pro-inflammatory cytokines during systemic inflammation. J Neuroimmunol 167: 90-98.

Wu Z, Tokuda Y, Zhang XW, Nakanishi H. 2008. Agedependent responses of glial cells and leptomeninges during systemic inflammation. Neurobiol Dis 32: $543-$ 551.

Zhang W, Wang T, Pei Z, Miller DS, Wu X, Block ML, Wilson B, Zhang W, Zhou Y, Hong JS, et al. 2005. Aggregated $\alpha$ synuclein activates microglia: A process leading to disease progression in Parkinson's disease. FASEB J 9: 533-542. 


\title{
$\&_{\mathrm{CSH}}^{\infty} \&$ Cold Spring Harbor

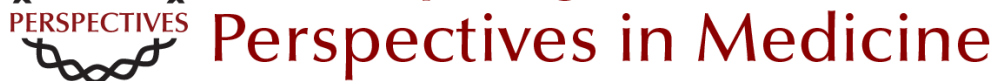

\section{Innate Inflammation in Parkinson's Disease}

\author{
V. Hugh Perry
}

Cold Spring Harb Perspect Med 2012; doi: 10.1101/cshperspect.a009373

Subject Collection Parkinson's Disease

Functional Neuroanatomy of the Basal Ganglia José L. Lanciego, Natasha Luquin and José A. Obeso

Animal Models of Parkinson's Disease: Vertebrate Genetics

Yunjong Lee, Valina L. Dawson and Ted M. Dawson

Innate Inflammation in Parkinson's Disease V. Hugh Perry

Parkinson's Disease and Parkinsonism:

Neuropathology

Dennis W. Dickson

Physiological Phenotype and Vulnerability in

Parkinson's Disease

$D$. James Surmeier, Jaime N. Guzman, Javier Sanchez, et al.

Clinical Approach to Parkinson's Disease:

Features, Diagnosis, and Principles of

Management João Massano and Kailash P. Bhatia

The Role of Autophagy in Parkinson's Disease Melinda A. Lynch-Day, Kai Mao, Ke Wang, et al.

Disruption of Protein Quality Control in Parkinson's Disease

Casey Cook, Caroline Stetler and Leonard Petrucelli

\section{Drosophila as a Model to Study Mitochondrial Dysfunction in Parkinson's Disease Ming Guo}

Parkinsonism Due to Mutations in PINK1, Parkin, and DJ-1 and Oxidative Stress and Mitochondrial Pathways Mark R. Cookson

Programmed Cell Death in Parkinson's Disease Katerina Venderova and David S. Park

Genomics and Bioinformatics of Parkinson's

Disease

Sonja W. Scholz, Tim Mhyre, Habtom Ressom, et al.

Motor Control Abnormalities in Parkinson's

Disease

Pietro Mazzoni, Britne Shabbott and Juan Camilo Cortés

Parkinson's Disease: Gene Therapies Philippe G. Coune, Bernard L. Schneider and Patrick Aebischer

Functional Neuroimaging in Parkinson's Disease Martin Niethammer, Andrew Feigin and David Eidelberg

Leucine-Rich Repeat Kinase 2 for Beginners: Six Key Questions Lauren R. Kett and William T. Dauer

For additional articles in this collection, see http://perspectivesinmedicine.cshlp.org/cgi/collection/ 